\title{
PREDICTICTING TELECOMMUTING PREFERENCES AND JOB OUTCOMES AMID COVID-19 PANDEMIC: A LATENT PROFILE ANALYSIS
}

\author{
CAFER BAKAÇ ${ }^{1}$ \\ TUM School of Management, Technical University Munich \\ 80335, Munich, Germany, cafer.bakac@tum.de \\ JETMIR ZYBERAJ $^{1}$ \\ University of Bamberg \\ JAMES C. BARELA \\ Technical University of Munich
}




\section{INTRODUCTION}

Telecommuting is defined as "a work practice that involves members of an organization substituting a portion of their typical work hours (ranging from a few hours per week to nearly full-time) to work away from a central workplace - typically principally from home — using technology to interact with others as needed to conduct work tasks" (Allen, Golden, \& Shockley, 2015: 44). This kind of practice substantially differs from the regular and ordinary modes of work because employees perform their usual work in different settings, usually from home (Allen et al., 2015). Although research has been conducted on telecommuting since the 1970s, it has recently become critical when life incidents, like the COVID-19 pandemic has forced many to work from home. Such events offer rare opportunities, for a wide range of researchers and from various fields, to study important questions that would not typically be able to be asked, such as about telecommuting experiences. We took this opportunity and conducted two studies regarding telecommuting, basing our rationale on the fact that many on-site employees were forced to work from home, across a wide range of occupations as a direct result of the pandemic (Kramer \& Kramer, 2020). The aim of our study, thus, was to investigate the preferences of employees who were forced to work from home. Specifically, by creating latent profiles from important work and personality related constructs, we aimed at predicting employees' preference for working from home or working on-site based on these profiles, and further investigate the relationship of these latent profiles to perceived productivity, job satisfaction, and job engagement.

We selected conscientiousness, extroversion, satisfaction of the general need for autonomy, and self-regulation, as important personality and motivational predictors of positive work outcomes. Findings have shown that, among Big Five personality characteristics, conscientiousness is the best predictor of job performance (Barrick \& Mount, 1991). Similarly, self-regulation strategies have also been reported as important for job-related outcomes such as job satisfaction, increased persistence, as well as job performance in general (Latham \& Locke, 2007; Neck \& Houghton, 2006). Furthermore, extraverts are shown to prefer environments that are highly stimulating, where social interaction is relatively common (Eyseneck, 1963), and extroversion has been demonstrated to be as one of the most consistent personality predictors of leadership (Blickle, Meurs, Wihler, Ewen, Merkl, \& Missfeld, 2015). In addition, satisfaction of the need for autonomy has been noted to be important for job performance by increasing motivation, interest, and engagement (Morgeson \& Humphrey, 2008; Niemiec \& Ryan, 2009).

By conducting these studies, we contribute to the literature and practice in several ways. For example, by predicting preferences for working from home or working on-site based on the personality and motivational characteristics of employees, we provide information that companies can utilize to leverage and maximize the efficiency of their workforce.

\section{METHODS}

\section{Participants}

To determine the number of participants needed to run latent profile analyses, in the first study, we relied on the previous research that was methodologically similar to ours (Bouckenooghe, Clercq, \& Raja, 2019; Chawla, MacGowan, Gabriel, \& Podsakoff, 2020), we concluded to gather data from at least 170 participants. First, we sent our survey out via several social media channels, which did not yield enough participants. Next we enlisted participants via 
Amazon Mechanical Turk (MTurk), which has been shown to be a valid method for collecting data (Bennett, Gabriel, Calderwood, Dahling, \& Trougakos, 2016). We had 221 participants (81 females, 126 participants in the age ranges of 25-29 and 30-34). For the second study, we relied on a more recent publication regarding the sample size requirements, which calls for increasing the sample size to over 500 for better and more reliable LPA (Spurk, Hirschi, Wang, Valero, \& Kauffeld, 2020). For our second study, we collected data from 510 participants through MTurk (179 females; 252 participants being in the age ranges of 25-29 and 30-34).

\section{Measures}

In both studies, we measured self-regulation, conscientiousness, extraversion, and need for autonomy to create latent profiles and job satisfaction, perceived productivity, home office preference, job engagement, intrinsic motivation, and emotion regulation as dependent variables and mediators. For a complete description of each measured variable in Study 1 and Study 2 (see pre-registrations: https://osf.io/3a25w/ and https://osf.io/q4732/).

\section{Data Analysis}

All of the analyses were conducted using R and SPSS. We, first, conducted latent profile analysis using the tidyLPA package (Rosenberg, Beymer, Anderson, van Lissa, \& Schmidt, 2018). In identifying varying numbers of latent profiles, different constraints can be placed on variance (varying or equal) and covariance (varying, zero, equal). For determining the optimal model and the number of profiles, Bayesian Information Criterion (BIC) has been considered as the best fit index for determining the number of profiles present in the data (Nylund, Asparouhov, \& Muthén, 2007). However, previous research has heavily relied on a multitude of fit indices such as adjusted BIC, the Akaike Information Criterion (AIC), the p-value of the bootstrap likelihood ratio test (BLRT), and Entropy. We also relied on these fit indices when determining the number of profiles in our data. Later, we compared the profiles based on selfregulation, conscientiousness, extraversion, and need for autonomy to support the qualitative differences of profiles. Most importantly, using the profiles as predictor, gender, age, marital status, number of children and the extent to which their job is telecommutable as control variables, and the preference for working from home or on-site as dependent variable, we conducted a logistic regression. In addition, we ran two mediation analyses with profiles as independent variables, work engagement as mediator and perceived productivity and job satisfaction as dependent variables. Each analysis was conducted separately for each study.

\section{RESULTS}

For correlations and descriptive statistics, see the links to the pre-registrations.

\section{Study 1}

The results showed that a solution with two latent profiles of differing variance and covariance was favored $(\mathrm{BIC}=1959)$, with a moderate certainty of classification (entropy $=.70)$. Further, this model showed not only the lowest BIC values, but also SABIC $($ SABIC $=1867)$ and AIC $($ AIC $=1960)$ in comparison to the other models and three profiles. Furthermore, a significant BLRT p-value indicated a significant improvement in comparison to one profile solution. The two profiles were quantitatively distinct: individuals with a high probability in the 
first profile showed significantly higher need for autonomy $(M=5.02, S D=1.08)$, and conscientiousness $(M=4.06, S D=0.81)$, and higher but not significant extraversion $(M=3.08$, $S D=1.15)$ and slightly lower but not significant self-regulation $(M=2.82, S D=0.58)$ than individuals with a higher likelihood to be in the second profile $(M=4.18, S D=0.33$ for need for autonomy; $M=2.98, S D=0.53$ for conscientiousness; $M=2.98, S D=0.44$ for extraversion; $M$ $=2.89, S D=0.41$ for self-regulation). Based on these values, we named our profiles as conscientious low self-regulated and self-regulated low conscientious.

Furthermore, results from a logistic regression demonstrated the model to be statistically significant, $\chi^{2}(8)=62.98, p<.00$. The model explained 38.0\% (Nagelkerke $R^{2}$ ) of the variance in home office preference and correctly classified $77.7 \%$ of cases. Self-regulated low conscientious were 3.64 times more likely to prefer working from home than conscientious low self-regulated $\left(b=1.29\right.$, Wald $\chi^{2}(1)=8.81, p<.001, O R=3.64(95 \%$ CI $[1.55,8.56])$.

In addition to these, two mediation analyses showed that the indirect effect of profiles (higher numbers indicating self-regulated low conscientious profile) on perceived productivity and job satisfaction through work engagement was found to be significant, $b=-.21, S E=.06$, $95 \%$ CI $[-.38,-.05]$ and $b=-.10, S E=.04,95 \%$ CI $[-.19,-.02]$ respectively.

\section{Study 2}

Following the same procedures as in study one and increasing our sample size to 510, we aimed to replicate the previous findings. To that end, we conducted an LPA and found a solution with two latent profiles of varying variance and covariance to be most favorable $(\mathrm{BIC}=4317)$, with a moderate certainty of classification (entropy $=.75)$. Further, this model showed not only the lowest BIC values, but also SABIC $(\mathrm{SABIC}=4224)$ and AIC $(\mathrm{AIC}=4194)$ in comparison to the other models and three profiles. Furthermore, a significant BLRT p-value indicated a significant improvement in comparison to one profile solution. The two profiles were quantitatively distinct: individuals with a high probability in the second profile showed significantly higher need for autonomy $(M=4.99, S D=1.00)$, and conscientiousness $(M=4.32, S D=0.76)$, but significantly lower extroversion $(M=2.94, S D=1.14)$ and self-regulation $(M=2.88, S D=0.58)$ than individuals with a higher likelihood to be in the first profile $(M=4.26, S D=0.38$ for need for autonomy; $M=2.94, S D=0.55$ for conscientiousness; $M=3.13, S D=0.47$ for extraversion; $M$ $=3.07, S D=0.46$ for self-regulation). Based on these values, we named our profiles as conscientious low self-regulated (for profile 2) and self-regulated low conscientious (for profile 1) as in Study 1.

Similar to Study 1, results from a logistic regression demonstrated the model to be statistically significant, $\chi^{2}(30)=105.06, p<.00$. The model explained $29.0 \%$ (Nagelkerke $R^{2}$ ) of the variance in home office preference and correctly classified $80.8 \%$ of cases. Self-regulated low conscientious were 2.14 times more likely to prefer working from home than conscientious low self-regulated $\left(b=.76\right.$, Wald $\chi^{2}(1)=6.41, p<.001, O R=2.14(95 \%$ CI $[1.19,3.86])$.

In addition to these, two mediation analyses showed that the indirect effect of profiles on perceived productivity and job satisfaction through work engagement was found to be nonsignificant. However, the direct effects were significant, showing that the conscientious low selfregulated reported higher job satisfaction than self-regulated low conscientious. 


\section{DISCUSSION}

This research investigated individuals' preferences of working from home or on-site based on profiles created from extraversion, conscientiousness, self-regulation, and the satisfaction of the need for autonomy. Further, it explored the differences between the profiles created in terms of perceived productivity and job satisfaction mediated by work engagement. For these, we conducted two studies. In the first study, the data resulted in two profiles and we named the profiles as self-regulated low-conscientious and conscientious low-self-regulated because the former showed high scores of self-regulation and extraversion while the latter showed high scores of satisfaction of the need for autonomy and conscientiousness. Individuals in the self-regulated low-conscientious profile showed higher levels of preference for working from home as opposed to the conscientious low-self-regulated profile. Further, the results demonstrated an indirect and direct effect of profiles (higher scores demonstrating conscientious low-self-regulated profile) on perceived productivity and job satisfaction through work engagement. For the second study, following suggestions from Spurk et al. (2020), we replicated the results from the first study with a larger sample size. Results revealed the same two profiles and the preferences for working from home or on-site were similarly associated with the profiles. For this second study, we could not replicate the mediation results. Nevertheless, we found significant effects of profiles (higher scores demonstrating conscientious low-self-regulated profile) on perceived productivity and job satisfaction.

Overall, our findings yield implications for both companies and managers. Accounting for profiles revealed, it is particularly important for companies to take the various profiles and their work preferences into account. For example, our findings showed that self-regulated lowconscientious individuals have a higher preference for working from home than working on-site. Thus, based on our profiles, organizations and leaders can make informed decisions about the types of people that would complement their teams, whether they are mostly working from home, or need to invest in more working space.

\section{ENDNOTES}

1. Authors contributed equally to this paper. 


\section{REFERENCES}

Allen, T. D., Golden, T. D., \& Shockley, K. M. 2015. How effective is telecommuting? Assessing the status of our scientific findings. Psychological Science in the Public Interest a Journal of the American Psychological Society, 16(2): 40-68.

Barrick, M. R., \& Mount, Michael, K. 1991. The big five personality dimensions and job performance: a meta-analysis. Personnel Psychology, 44(1): 1-26.

Bennett, A. A., Gabriel, A. S., Calderwood, C., Dahling, J. J., \& Trougakos, J. P. 2016. Better together? Examining profiles of employee recovery experiences. The Journal of Applied Psychology, 101(12): 1635-1654.

Blickle, G., Meurs, J. A., Wihler, A., Ewen, C., Merkl, R., \& Missfeld, T. 2015. Extraversion and job performance: How context relevance and bandwidth specificity create a non-linear, positive, and asymptotic relationship. Journal of Vocational Behavior, 87: 80-88.

Bouckenooghe, D., Clercq, D. de, \& Raja, U. 2019. A person-centered, latent profile analysis of psychological capital. Australian Journal of Management, 44(1): 91-108.

Chawla, N., MacGowan, R. L., Gabriel, A. S., \& Podsakoff, N. P. 2020. Unplugging or staying connected? Examining the nature, antecedents, and consequences of profiles of daily recovery experiences. The Journal of Applied Psychology, 105(1): 19-39.

Eysenck, H. J. 1963. Biological basis of personality. Nature, 199: 1031-1034.

Kramer, A., \& Kramer, K. Z. 2020. The potential impact of the Covid-19 pandemic on occupational status, work from home, and occupational mobility. Journal of Vocational Behavior: 103442.

Latham, G. P., \& Locke, E. A. 2007. New developments in and directions for goal-Setting Research. European Psychologist, 12(4): 290-300.

Morgeson, F. P., \& Humphrey, S. E. 2008. Job and team design: Toward a more integrative conceptualization of work design. In J. J. Martocchio (Ed.), Research in Personnel and Human Resources Management: Vol. 27: 39-91. Bingley, U.K: Emerald.

Neck, C. P., \& Houghton, J. D. 2006. Two decades of self-leadership theory and research. Journal of Managerial Psychology, 21(4): 270-295.

Niemiec, C. P., \& Ryan, R. M. 2009. Autonomy, competence, and relatedness in the classroom. Theory and Research in Education, 7(2): 133-144.

Nylund, K. L., Asparouhov, T., \& Muthén, B. O. 2007. Deciding on the number of classes in latent class analysis and growth mixture modeling: A monte carlo simulation study. Structural Equation Modeling: A Multidisciplinary Journal, 14(4): 535-569.

Rosenberg, J., Beymer, P., Anderson, D., van Lissa, C.j., \& Schmidt, J. 2018. TidyLPA: An r package to easily carry out latent profile analysis (lpa) using open-source or commercial software. Journal of Open Source Software, 3(30): 978.

Spurk, D., Hirschi, A., Wang, M., Valero, D., \& Kauffeld, S. 2020. Latent profile analysis: A review and "how to" guide of its application within vocational behavior research. Journal of Vocational Behavior, 120: 103445. 